\title{
Changing patterns in clinical-histological presentation and renal outcome over the last five decades in a cohort of 499 patients with lupus nephritis
}

\author{
Gabriella Moroni, ${ }^{1}$ Paolo Gilles Vercelloni, ${ }^{2}$ Silvana Quaglini, ${ }^{3}$ Mariele Gatto, ${ }^{4}$ \\ Davide Gianfreda, ${ }^{5}$ Lucia Sacchi, ${ }^{3}$ Francesca Raffiotta, ${ }^{1}$ Margherita Zen, ${ }^{4}$ \\ Gloria Costantini, ${ }^{4}$ Maria Letizia Urban, ${ }^{5}$ Federico Pieruzzi, ${ }^{2}$ Piergiorgio Messa, \\ Augusto Vaglio, ${ }^{5}$ Renato Alberto Sinico, ${ }^{2}$ Andrea Doria ${ }^{4}$
}

\begin{abstract}
Handling editor Josef $S$
Smolen

Additional material is published online only. To view please visit the journal online (http://dx.doi.org/10.1136/ annrheumdis-2017-212732)
\end{abstract}

${ }^{1}$ Nephrology Unit, Fondazione IRCCS Ca' Granda Ospedale Maggiore Policlinico, Milano, Italy

${ }^{2}$ Nephrology Unit, University of Milano Bicocca, Milano, Italy ${ }^{3}$ Department of Electrical, Computer and Biomedical Engineering, University of Pavia, Pavia, Italy

${ }^{4}$ Division of Rheumatology, Department of Medicine, DIMED, University of Padua, Padua, Italy

${ }^{5}$ Nephrology Unit, University Hospital, Parma, Parma, Italy

\section{Correspondence to}

Dr Gabriella Moroni, Divisione di Nefrologia e Dialisi, Fondazione IRCCS Cà Granda Ospedale Maggiore Policlinico, Milano 20122, Italy;

gmoroni@policlinico.mi.it

RAS and $A D$ contributed equally.

Received 21 November 2017

Revised 13 April 2018

Accepted 16 April 2018

Published Online First

5 May 2018

\section{ABSTRACT}

Objectives To evaluate changes in demographic, clinical and histological presentation, and prognosis of lupus nephritis (LN) over time.

Patients and methods We studied a multicentre cohort of 499 patients diagnosed with LN from 1970 to 2016. The 46-year follow-up was subdivided into three periods (P): P1 1970-1985, P2 1986-2001 and P3 2002-2016, and patients accordingly grouped based on the year of LN diagnosis. Predictors of patient and renal survival were investigated by univariate and multivariate proportional hazards Cox regression analyses. Survival curves were compared using the log-rank test.

Results A progressive increase in patient age at the time of $L N$ diagnosis $(p<0.0001)$ and a longer time between systemic lupus erythematosus onset and LN occurrence $(p<0.0001)$ was observed from 1970 to 2016. During the same period, the frequency of renal insufficiency at the time of LN presentation progressively decreased $(p<0.0001)$ and that of isolated urinary abnormalities increased $(p<0.0001)$. No changes in histological class and activity index were observed, while chronicity index significantly decreased from 1970 to 2016 ( $p=0.023)$. Survival without end-stage renal disease (ESRD) was $87 \%$ in $\mathrm{P} 1,94 \%$ in $\mathrm{P} 2 \%$ and $99 \%$ in $\mathrm{P} 3$ at 10 years, $80 \%$ in $\mathrm{P} 1$ and $90 \%$ in $\mathrm{P} 2$ at 20 years $(p=0.0019)$. At multivariate analysis, male gender, arterial hypertension, absence of maintenance immunosuppressive therapy, increased serum creatinine, and high activity and chronicity index were independent predictors of ESRD.

Conclusions Clinical presentation of LN has become less severe in the last years, leading to a better long-term renal survival.

\section{INTRODUCTION}

Lupus nephritis (LN) is a frequent and severe manifestation of systemic lupus erythematosus (SLE) and is characterised by a relapsing and remitting clinical course. ${ }^{1-4}$ Renal involvement occurs at the time of SLE diagnosis or during the course of the disease in up to two-thirds of patients. ${ }^{56}$ Clinical presentation predictor of death and end-stage renal disease (ESRD), ${ }^{8} 9$ both patient and renal survival have significantly improved in the last few decades ${ }^{10-13}$ and the rate of renal flares has considerably decreased over time as well. ${ }^{3}$ The improvement in LN prognosis has been attributed to many factors including the better understanding of SLE pathogenesis, new treatment options and strategies, and improved management of hypertension, infections and other comorbidities. ${ }^{14}$

To the best of our knowledge, no studies have evaluated whether changes in demographic, clinical and histological features at the time of LN presentation have occurred over the last decades and whether these changes have had an influence on the disease management and outcome.

The objective of our study was to examine the changes in demographic, clinical and histological features at the time of LN onset in a large cohort of patients during a 46-year follow-up. We looked at changes in LN prognosis during the course of the follow-up and searched for the prognostic factors associated with patient and renal outcomes.

\section{PATIENTS AND METHODS}

Four hundred and ninety-nine patients were included in this retrospective study of prospectively collected data. Inclusion criteria were American College of Rheumatology criteria-based diagnosis of SLE ${ }^{15}$ and biopsy-proven LN performed between January 1970 and December 2016. Patients were followed in four Italian referral centres: Renal Divisions of Ospedale Maggiore Milano, San Carlo Hospital Milano and University of Parma, and Rheumatology Unit of Padova University. Since the 1980 s, according to the good clinical practice, patients undergoing renal biopsy in Italy signed informed consent that includes the consent for using clinical data for scientific purposes, while in previous years no consent was required for this type of studies. The study was approved by the local ethics committees. The 46-year follow-up was subdivided into three periods (P), 15 years varies from asymptomatic urinary abnormalities to chronic irreversible renal insufficiency. ${ }^{7}$ Although renal involvement is still considered a strong each: P1 from January 1970 to December 1985 , P2 from January 1986 to December 2001 and P3 from January 2002 to December 2016, and patients

Vercelloni PG, Quaglini $S_{\text {, }}$

etal. Ann Rheum Dis

1318

Moroni G, et al. Ann Rheum Dis 2018;77:1318-1325. doi:10.1136/annrheumdis-2017-212732 
accordingly grouped based on the year of LN diagnosis. Detailed data on the source population and study design are reported in table 1 and online supplementary text $\mathrm{S} 1$. Notably, $70.3 \%$ of the overall source population had biochemical and/or urinary abnormalities of lupus nephritis. The high proportion of patients with LN is due to the fact that three of the four centres participating in this study were Nephrology Units.

All patients received a renal biopsy that was classified according to the International Society of Nephrology/Renal Pathology Society (IRS/RPS) classification criteria. ${ }^{16}$ Since 2003, all renal biopsies performed before 2002 were reclassified according to the same IRS/RPS classification criteria by the clinicians and pathologists based on written reports of light microscopy and immunofluorescence or the re-evaluation of slides, where necessary. Activity and chronicity indices were calculated according to the score proposed by Austin et al. ${ }^{17}$ Estimated glomerular filtration rate (eGFR) was calculated according to the Cockcroft and Gault formula based on gender, serum creatinine, age and body weight of the patients. Normal renal function was defined as serum creatinine $\leq 1 \mathrm{mg} / \mathrm{dL}$ and eGFR $>60 \mathrm{~mL} / \mathrm{min}$ that correspond to the definition of CKD 1 and 2. Proteinuria was measured by benzethonium chloride on the urine collected over 24 hours expressed as grams per 24 hours. Arterial hypertension was defined as the mean of three consecutive measurements

\begin{tabular}{|c|c|c|c|c|c|}
\hline & Overall & P1 & P2 & P3 & $P$ values \\
\hline \multicolumn{6}{|l|}{ (A) Source population } \\
\hline All patients with SLE, N & 793 & 162 & 249 & 382 & - \\
\hline Patients with LN, N (\%) & $557(70.2)$ & $124(76.5)$ & $174(69.8)$ & $259(67.8)$ & ns \\
\hline Patients with renal biopsy, N (\%)* & $499(89.6)$ & $106(85.5)$ & $158(90.8)$ & $235(90.7)$ & ns \\
\hline Patients without renal biopsy, N (\%)* & $58(6.1)$ & $18(14.5)$ & $16(9.2)$ & $24(9.3)$ & ns \\
\hline Lost to follow-up, N (\%) & $21(3.7)$ & $2(1.2)$ & $6(2.4)$ & $13(3.4)$ & ns \\
\hline \multicolumn{6}{|l|}{ (B) Clinical features of patients with renal biopsy } \\
\hline & Overall 499 patients & P1 106 patients & P2 158 patients & P3 235 patients & \\
\hline Gender, female, N (\%) & $427(85.6)$ & $99(93.4)$ & $139(88)$ & $189(80.4)$ & 0.004 \\
\hline Age at SLE diagnosis, years & $28.11 \pm 12.0$ & $27 \pm 10.3$ & $26.3 \pm 11.2$ & $29.8 \pm 13$ & 0.01 \\
\hline Age at LN diagnosis, years & $31.4 \pm 12.5$ & $28.4 \pm 10.4$ & $29 \pm 11.5$ & $34.4 \pm 13.3$ & 0.001 \\
\hline Disease duration before $L N$ diagnosis, years & $3.3 \pm 5.3$ & $1.3 \pm 1.3$ & $2.6 \pm 4.5$ & $4.6 \pm 6.3$ & $<0.0001$ \\
\hline Follow-up duration, years & $12.7 \pm 9.8$ & $20.5 \pm 13$ & $15.8 \pm 7.8$ & $6.8 \pm 4.3$ & \\
\hline Weight, kg & $61.7 \pm 12.2$ & $57.4 \pm 10.4$ & $62 \pm 11.2$ & $63.3 \pm 13.1$ & ns \\
\hline Hypertension, N (\%) & $240(48.2 \%)$ & $56(52.8 \%)$ & $77(48.7 \%)$ & $107(45.9 \%)$ & ns \\
\hline Serum creatinine, $\mathrm{mg} / \mathrm{dL}$ & $1.2 \pm 1.1$ & $1.8 \pm 1.8$ & $1.2 \pm 0.8$ & $1.0 \pm 0.7$ & $<0.0001$ \\
\hline Creatinine clearance, $\mathrm{mL} / \mathrm{min}$ & $86.3 \pm 41$ & $72.2 \pm 45.1$ & $83.7 \pm 36.6$ & $94.1 \pm 40.2$ & 0.0001 \\
\hline Proteinuria, g/24hours & $4.1 \pm 3.7$ & $3.6 \pm 2.7$ & $4.5 \pm 4.0$ & $4.1 \pm 3.9$ & ns \\
\hline Urinary erythrocytes/HPF & $27.7 \pm 45.7$ & $18.6 \pm 18.6$ & $24.2 \pm 24.3$ & $34.1 \pm 61.9$ & 0.01 \\
\hline Serum albumin, g/dL & $3.0 \pm 0.7$ & $2.7 \pm 0.7$ & $3.0 \pm 0.7$ & $3 \pm 0.7$ & 0.005 \\
\hline Haematocrit, \% & $33.5 \pm 6.2$ & $33.3 \pm 7.3$ & $33.8 \pm 5.5$ & $33.4 \pm 6$ & ns \\
\hline White blood cells $/ 10^{3} / \mathrm{mL}$ & $6252 \pm 3223$ & $6258 \pm 2842$ & $6180 \pm 2888$ & $6299 \pm 3603$ & ns \\
\hline Platelets/109/L & $240302 \pm 96198$ & $230422 \pm 103282$ & $252193 \pm 97365$ & $236641 \pm 91640$ & ns \\
\hline $\mathrm{C} 3, \mathrm{mg} / \mathrm{dL}$ & $62.1 \pm 25.4$ & $65.1 \pm 22.6$ & $58.7 \pm 25.4$ & $63.1 \pm 26.3$ & ns \\
\hline $\mathrm{C} 4, \mathrm{mg} / \mathrm{dL}$ & $13.7 \pm 14.3$ & $20.7 \pm 20.2$ & $14.7 \pm 15.8$ & $10.2 \pm 8$ & 0.001 \\
\hline Anti-dsDNA, positive N (\%) (NA 25) & $414(87.3)$ & $82(93.6)$ & $128(85.3)$ & $204(90.3)$ & ns \\
\hline Urinary abnormalities & $203(40.7)$ & $28(26.4)$ & $60(38)$ & $115(48.9)$ & $<0.0001$ \\
\hline Nephrotic syndrome & $174(34.9)$ & $32(30.2)$ & $59(37.3)$ & $83(35.4)$ & ns \\
\hline Nephritic syndrome & $92(18.4)$ & $31(29.2)$ & $32(20.3)$ & $29(12.4)$ & 0.0001 \\
\hline Rapidly progressive renal insufficiency & $30(9.0)$ & $15(14.2)$ & $7(3.9)$ & $8(3.4)$ & $<0.0001$ \\
\hline \multicolumn{6}{|l|}{ Histological classes, N (\%) } \\
\hline II & $22(4.4)$ & $5(4.8)$ & $4(2.5)$ & $13(5.5)$ & ns \\
\hline $\mathrm{III \dagger}$ & $115(23.1)$ & $23(21.9)$ & $28(17.8)$ & $64(27.2)$ & ns \\
\hline IV† & $267(53.7)$ & $56(53.3)$ & $91(58)$ & $120(51.1)$ & ns \\
\hline V & $93(18.7)$ & $21(20)$ & $34(21.7)$ & $38(16.2)$ & ns \\
\hline $\mathrm{VI}$ & $2(0.4)$ & $1(0.9)$ & $1(0.6)$ & $0(0)$ & ns \\
\hline Activity index & $6.4 \pm 4.9$ & $6.2 \pm 4.9$ & $6.6 \pm 4.9$ & $5.9 \pm 4.5$ & ns \\
\hline Chronicity index & $2.0 \pm 2.2$ & $2.6 \pm 2.5$ & $2.0 \pm 2.2$ & $1.6 \pm 2$ & 0.0023 \\
\hline
\end{tabular}

(A) Number of patients with SLE followed in the four centres (three Nephrology Units and one Rheumatology Unit) and number of patients with clinical diagnosis of lupus nephritis who underwent or did not undergo renal biopsy, overall and subdivided according to the different periods. (B) Clinical features at the time of lupus nephritis diagnosis in patients who underwent renal biopsy, overall and according to the three different periods. P values refer to $t$-test, Kruskal-Wallis test or $\chi^{2}$ test (with $2 \mathrm{df}$ ), according to the type and distribution of variables.

*Percentages refer to the number of patients who received renal biopsy $(n=557)$.

tClass III+V: overall, four patients; $\mathrm{P} 1$, three patients; $\mathrm{P2}$, one patient, $\mathrm{P} 3$, no cases. Class IV+V: overall, 31 patients; $\mathrm{P} 1,2$ patients, $\mathrm{P2}, 8$ patients; $\mathrm{P} 3,21$ patients. P, period; P1: 1970-1985; P2: 1986-2001; P3: 2002-2016.

C3/C4, complement components; HPF, high-power field; LN, lupus nephritis; NA, not available; N, number; ns, not significant; SLE, systemic lupus erythematosus. 
of systolic blood pressure $>140 \mathrm{~mm} \mathrm{Hg}$ and/or diastolic blood pressure $>90 \mathrm{~mm} \mathrm{Hg}$ in sitting position. Data on death were obtained from hospital charts for patients who died in hospital and through information obtained from relatives for other patients.

\section{Definitions}

Clinical syndromes at presentation were defined as follows:

- Isolated urinary abnormalities: normal renal function, proteinuria $<3.5 \mathrm{~g} / 24$ hours and $>0.5 \mathrm{~g} / 24$ hours, and/or microscopic haematuria (urinary red blood cells $>5 /$ highpower field (HPF)) after having excluded non-renal causes;

- Nephrotic syndrome: normal renal function, proteinuria $>3.5 \mathrm{~g} / 24$ hours and serum albumin $<3.5 \mathrm{~g} / \mathrm{dL}$;

- Acute nephritic syndrome: acute renal dysfunction (serum creatinine $>1 \mathrm{mg} / \mathrm{dL}$ and eGFR $<60 \mathrm{~mL} / \mathrm{min}$ ), macroscopic or severe microscopic haematuria (urinary red blood cells $>20 / \mathrm{HPF}$ ) and/or erythrocyte casts, arterial hypertension and variables degrees of proteinuria;

- Rapidly progressive renal insufficiency: rapid deterioration of renal function leading to CKD stage 3 to 5 within a few weeks, with oliguria, arterial hypertension and severe haematuria.

- Renal states at last observation were defined as follows: complete renal remission, serum creatinine $<1 \mathrm{mg} /$ $\mathrm{dL}$ with eGFR $>60 \mathrm{~mL} / \mathrm{min}$, proteinuria $<0.5 \mathrm{~g} /$ day and inactive urinary sediment; partial renal remission, serum creatinine $<1 \mathrm{mg} / \mathrm{dL}$ with $\mathrm{eGFR}>60 \mathrm{~mL} / \mathrm{min}$ and proteinuria $<3.5 \mathrm{~g} /$ day and $\geq 0.5 \mathrm{~g} /$ day; $\mathrm{CKD}$, serum creatinine $>1.0 \mathrm{mg} / \mathrm{dL}$ with $\mathrm{eGFR}<60 \mathrm{~mL} / \mathrm{min}$ and inactive urinary sediment, confirmed by at least three determinations; ESRD, the need of renal replacement therapy; Poor renal outcome, CKD or ESRD.

\section{Statistical analysis}

Mean \pm SD or median and IQR were used for descriptive statistics, according to variable distribution. Temporal trends of clinical parameters were tested through Pearson or Spearman correlation analysis, according to parametric or non-parametric variable distribution. Survival curves were drawn using the Kaplan-Meier estimate and compared using the log-rank test. Univariate and multivariate proportional hazards Cox regression analyses were used to investigate the prognostic value of continuous and binary (dichotomised) variables. Patients lost to follow-up were 2/106 (1.9\%) in P1, 6/158 (3.8\%) in P2 and $13 / 235(5.5 \%)$ in P3. These low numbers of patients and the lack of a significant clinical deterioration at their last available follow-up suggest that censoring due to loss to follow-up was likely to be minimal and non-informative. The statistical package S-Plus was used to analyse sample data. ${ }^{18}$

\section{RESULTS}

\section{Demographic characteristics}

Four hundred and ninety-nine patients (427 women, 85.6\%) were included in the study; they were followed for a median period of 10.6 years (IQR 4-18). All but 51 (10.2\%) patients were Caucasian. Demographic, clinical and histological features of the cohort at the time of LN diagnosis are reported in table 1. The cohort was subdivided into three groups according to the year of LN diagnosis: group 1 included 106 patients (21\%) diagnosed with LN in P1; group 2 encompassed 158 patients (32\%) diagnosed with LN in P2; group 3 comprised 235 patients (47\%) diagnosed with LN in P3.
A

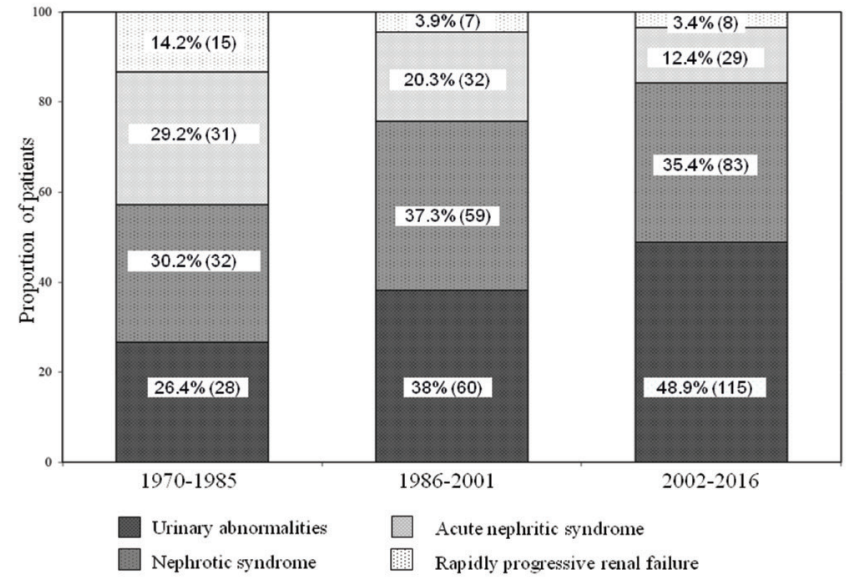

B

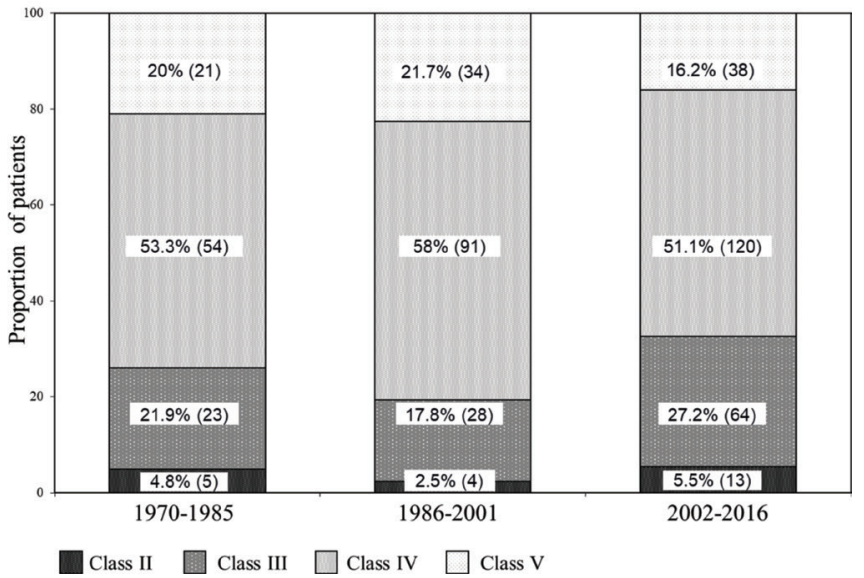

Figure 1 (A) Clinical syndrome at presentation of lupus nephritis in three different periods. (B) Histological classes at renal biopsy in three different periods.

The number of male patients progressively increased over the three periods: $6.6 \%$ in $\mathrm{P} 1,12 \%$ in $\mathrm{P} 2$ and $19.6 \%$ in P3 ( $\mathrm{p}=0.004)$. The lag time between SLE and LN diagnosis $(\mathrm{p}<0.0001)$ progressively increased from 1970 to 2016. The mean age at the time of LN occurrence increased from $28.4 \pm 10.4$ in P1 to $29 \pm 11.5$ in $\mathrm{P} 2$, and to $34.4 \pm 13.3$ in $\mathrm{P} 3(\mathrm{p}<0.001)$.

\section{Clinical and histological presentation}

The mean values of serum creatinine progressively decreased overtime: $1.8 \pm 1.8 \mathrm{mg} / \mathrm{dL}$ in $\mathrm{P} 1,1.2 \pm 0.8 \mathrm{mg} / \mathrm{dL}$ in $\mathrm{P} 2$ and $1.0 \pm 0.7 \mathrm{mg} / \mathrm{dL}$ in P3 $(\mathrm{p}<0.0001)$. Consistently, a significant decrease in the frequency of acute nephritic syndrome $(\mathrm{p}=0.0001)$ and rapidly progressive renal insufficiency $(p=0.0001)$ was observed, together with a significant increase in the prevalence of isolated urinary abnormalities from the first to the third period $(p<0.001)$ (figure $1 \mathrm{~A})$. The rate of nephrotic syndrome presentation was similar in the three periods. Creatinine serum levels, eGFR, proteinuria and urinary red blood cells in patients with the different clinical syndromes at the time of LN diagnosis by the three periods are reported in online supplementary table S1.

No differences in the percentage of histological classes in the three periods were observed (table 1 and figure 1B). Interestingly, an increase in mixed forms (class III+IV and IV+V) from P1 (4.7\% of cases) to P2 (12.6\%) and P3 (17.4\%) $(\mathrm{p}=0.006)$ was 
Table 2 Induction and maintenance therapy, and outcomes in all patients and according to the three different periods

\begin{tabular}{|c|c|c|c|c|c|}
\hline & Overall 499 patients & P1 106 patients & P2 158 patients & P3 235 patients & $P$ values \\
\hline Methylprednisolone pulses, N (\%) & $351(70.3)$ & $63(67.7)$ & $120(83.9)$ & $168(73.7)$ & 0.01 \\
\hline \multicolumn{6}{|l|}{ Immunosuppressive drugs, induction } \\
\hline None, N (\%) & $66(13.2)$ & $28(29)$ & $26(17.9)$ & $12(5.4)$ & $<0.0001$ \\
\hline Cyclophosphamide, N (\%) & $258(51.7)$ & $49(51)$ & $95(65.5)$ & $114(51.3)$ & 0.016 \\
\hline Azathioprine, N (\%) & $42(8.4)$ & $15(15.6)$ & $18(12.4)$ & $9(4.0)$ & $<0.0001$ \\
\hline Mycophenolate, N (\%) & $79(15.8)$ & 0 & $4(2.7)$ & $75(33.8)$ & $<0.0001$ \\
\hline Others* ${ }^{*} \mathrm{~N}(\%)$ & $17(3.4)$ & $3(3.1)$ & $2(1.4)$ & $12(5.4)$ & ns \\
\hline \multicolumn{6}{|c|}{ Immunosuppressive drugs, maintenance } \\
\hline None, N (\%) & $140(28)$ & $66(68.7)$ & $50(34)$ & $24(10.9)$ & $<0.0001$ \\
\hline Cyclophosphamide, N (\%) & $7(1.4)$ & $1(1)$ & $5(3.4)$ & $1(0.45)$ & ns \\
\hline Azathioprine, N (\%) & $152(30.4)$ & $27(28)$ & $58(39)$ & $67(30.6)$ & ns \\
\hline Mycophenolate, N (\%) & $143(28.6)$ & $1(1)$ & $22(15.1)$ & $120(54.8)$ & $<0.0001$ \\
\hline Others*, N (\%) & $18(3.6)$ & 0 & $11(7.5)$ & $7(3.2)$ & ns \\
\hline \multicolumn{6}{|l|}{ Outcomes† } \\
\hline Partial renal remission, N (\%) & $122(25.5)$ & $7(6.9)$ & $43(28.1)$ & $72(32.1)$ & $<0.0001$ \\
\hline Complete renal remission, $\mathrm{N}(\%)$ & $246(51.4)$ & $41(49.6)$ & $74(48.4)$ & $131(58.5)$ & 0.01 \\
\hline CKD, N (\%) & $31(6.4)$ & $8(7.9)$ & $13(8.5)$ & $10(4.5)$ & $<0.0001$ \\
\hline ESRD, N (\%) & $42(8.8)$ & $25(24.8)$ & $14(9.1)$ & $3(1.3)$ & $<0.0001$ \\
\hline Death, N (\%) & $37(7.7)$ & $20(19.8)$ & $9(5.9)$ & $8(3.6)$ & $<0.0001$ \\
\hline
\end{tabular}

P, period; P1: 1970-1985; P2:1986-2001; P3: 2002-2016. P values refer to $\chi^{2}$ test with $2 \mathrm{df}$.

*'Others' includes ciclosporin $A$, methotrexate, rituximab.

tOutcome was available in 478 patients (P1, 101 patients; $P 2,153$ patients; $P 3,224$ patients).

CKD, chronic kidney disease; ESRD, end-stage renal disease.

noted. Activity index did not significantly change over the three periods either when all the classes were considered (table 1) or when patients with class III $(4.95 \pm 2.9$ in P1, 5.6 \pm 3.1 in P2 and $5.9 \pm 4.5$ in $\mathrm{P} 3, \mathrm{p}=\mathrm{ns})$ and class IV (9.4 44.9 in P1, 9.4 \pm 3.7 in P2 and $9.4 \pm 3.8$ in $P 3, p=n s$ ) were separately analysed. Conversely, chronicity index significantly decreased $(p=0.0023)$ from P1 to P3 (table 1).

\section{Treatment}

More than two-thirds of patients in each period were treated with methylprednisolone pulses as induction therapy. In P1, 29\% of patients received corticosteroids alone for induction therapy in comparison with $17.9 \%$ in $\mathrm{P} 2 \%$ and $5.4 \%$ in $\mathrm{P} 3(\mathrm{p}<0.0001)$. Immunosuppressive drugs were added to corticosteroids for maintenance therapy in $30.5 \%$ of patients in $\mathrm{P} 1,65.5 \%$ in $\mathrm{P} 2 \%$ and $89.1 \%$ in P3 $(\mathrm{p}<0.0001)$. The immunosuppressive drugs used in induction and maintenance therapy during the three periods are reported in table 2. More than 50\% of patients in each period received cyclophosphamide as induction therapy (online supplementary table S2). A decrease in the use of azathioprine as induction therapy from P1 to P3 was counterbalanced by an increase in the use of mycophenolate mofetil (MMF). As far as maintenance therapy is concerned, the proportion of patients receiving azathioprine remained stable in the first two periods and decreased in the third period $(p<0.0001)$, while MMF use significantly increased in the last period compared with the previous ones $(\mathrm{p}<0.0001)$. Notably, the proportion of patients who were not treated with induction therapies progressively decreased over time $(\mathrm{p}<0.0001)$.

\section{Renal outcome and predictors of renal survival}

Outcome was available in 478 patients (95.8\%) (table 2). At last observation, complete renal remission was observed in $49.6 \%$ of patients in $\mathrm{P} 1,48.4 \%$ in $\mathrm{P} 2 \%$ and $58.5 \%$ in $\mathrm{P} 3(\mathrm{p}=0.01)$ (table 2). CKD and ESRD occurred in $7.9 \%$ and $24.8 \%$ of patients in $\mathrm{P} 1$, in $8.5 \%$ and $9.1 \%$ in $\mathrm{P} 2$ and in $4.5 \%$ and in $1.3 \%$ in $\mathrm{P} 3$, respectively $(\mathrm{p}<0.0001$ for all comparisons). Twenty patients in P1 died (19.8\%), in comparison with 9 (5.9\%) in $\mathrm{P} 2$ and $8(3.6 \%)$ in $\mathrm{P} 3(\mathrm{p}<0.0001)$. The CKD-free survival at 10 and at 20 years was $75 \%$ and $66 \%$ in P1, $85.5 \%$ and $80.2 \%$ in $\mathrm{P} 2 \%$, and $91.5 \%$ in $\mathrm{P} 3$, respectively $(\mathrm{p}=0.0069)$ (figure $2 \mathrm{~A}$ ). The ESRD-free survival at 10 and at 20 years were respectively $87 \%$ and $80 \%$ in $\mathrm{P} 1,94 \%$ and $90 \%$ in $\mathrm{P} 2 \%$, and $99 \%$ in P3, respectively $(p=0.0019)$ (figure $2 B$ ). Predictors of CKD and ESRD at univariate analyses are reported in table 3.

At multivariate analysis, carried out in the entire cohort, several factors at the time of the diagnosis of LN were independently associated with poor renal outcomes (CKD or ESRD) including baseline serum creatinine, high activity and chronicity index, arterial hypertension and the absence of maintenance immunosuppressive therapy (table 4). In addition, male gender, older age and high serum creatinine were predictors of death (table 4).

\section{DISCUSSION}

Our study outlines the most significant changes observed during the last five decades in demographic, clinical and histological features of $\mathrm{LN}$ at presentation. These results were drawn from a large multicentric cohort of patients followed in four Italian referral centres from 1970 to 2016 . In order to identify changes in LN presentation, the whole observational time was subdivided into three periods, 15 years each.

Historically, from 1970 to 1985 (P1) corticosteroid monotherapy was progressively replaced by combination treatment of corticosteroids with either azathioprine or cyclophosphamide probably due to the results of a pooled analysis that showed the superiority of combined immunosuppressive regimens over corticosteroids alone. ${ }^{19}$ Intravenous methylprednisolone pulses were also largely used in this period. ${ }^{20}{ }^{21}$ From 1986 to 2001 (P2), high-dose intravenous cyclophosphamide was commonly used as 

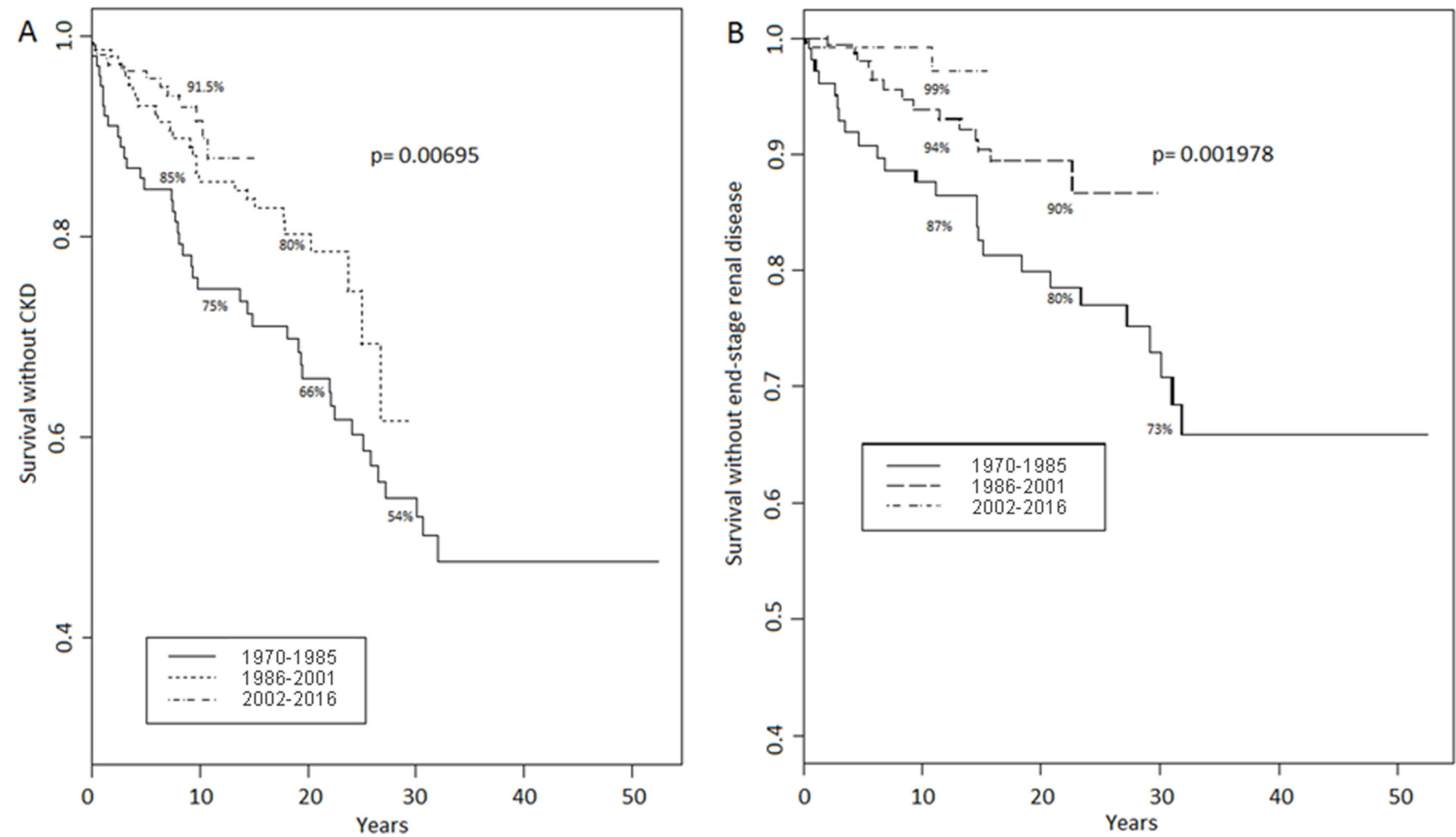

Figure 2 (A) Survival without chronic kidney disease (CKD) in three different periods. (B) Survival without end-stage renal disease in three different periods.

induction and maintenance therapy following the positive results of long-term controlled trials carried out at the National Institutes of Health. ${ }^{22}$ In the same period, the use of a combined oral immunosuppressive regimen as maintenance therapy became progressively more popular. ${ }^{23}$ Interestingly, the proportion of our patients who received steroids alone as induction therapy decreased from 29\% in P1\% to $18 \%$ in P2 and further declined to 5\% in P3. Finally, from 2002 to 2016 (P3), the evidence that MMF has a similar efficacy compared with cyclophosphamide in the induction phase and is more effective than azathioprine in the maintenance phase led to an increase in the use of MMF for induction as well as for maintenance therapy. ${ }^{24-26}$

The age of our patients at LN diagnosis progressively increased from 1970 to 2016 and LN developed progressively later after the onset of SLE. These changes may result from an earlier diagnosis of SLE, which leads to a closer surveillance of LN over time and, in turn, allows the identification of mild disease phenotypes, as well as from the earlier and more appropriate therapeutic intervention that includes the extensive use of antimalarial drugs, ${ }^{27} \mathrm{MMF}^{29} 30$ and biological drugs ${ }^{31} 32$ capable of hindering the development of LN.

The most interesting and innovative observation of our study is the progressively milder clinical presentation of LN from P1 to $\mathrm{P} 3$. Presentation with isolated urinary abnormalities significantly increased from $25 \%$ in $\mathrm{P} 1$ to about $50 \%$ in P3. This finding was accompanied by the progressive decrease in the frequency of renal insufficiency at presentation, while the percentage of nephrotic syndrome did not significantly change over time. The decreased severity in clinical presentation from 1970 to 2016 is in keeping with the progressive decline in serum creatinine at the time of LN diagnosis, which is one of the most important predictors of renal adverse outcome in short-term and long-term follow-up. ${ }^{173334}$
Nevertheless, the distribution of the renal histological classes was similar in the three periods regardless of clinical presentation. Class IV accounted for more than $50 \%$ of cases in all periods, followed by class III in 25\%, class V in around $20 \%$ and class II in a minority of patients. There was a significant increase from $\mathrm{P} 1$ to $\mathrm{P} 3$ in mixed classes (class III $+\mathrm{V}$ and class IV $+\mathrm{IV}$ ) that are considered to be associated with the worst prognosis in some ${ }^{35} 36$ but not all studies. ${ }^{37} 38$ Activity index remained unchanged from P1 to P3 either when we considered all histological classes or class III and IV separately. These data are consistent with the discrepancy between clinical and histological severity of LN at presentation reported in previous studies. ${ }^{7}$ Proliferative forms of LN were observed even in the absence of urinary abnormalities, ${ }^{39} 40$ suggesting that a certain amount of time is required for histological lesions to give rise to clinical manifestations. On the other hand, the early diagnosis of renal involvement in recent years can account for the lower severity of clinical presentation, which is in accordance with the significant progressive decrease in the chronicity index from P1 to P3. Moreover, in the last decades, the indication to renal biopsy has become wider due to the decrease in post-biopsy complications, which has led to perform renal biopsy in a number of patients with less severe urinary abnormalities. The increasing number of class III and class IV LN diagnosed with isolated urinary abnormalities, yet with high activity index (unchanged over the three periods), has important implications in clinical practice. Indeed, this result emphasises once again the importance of renal biopsy in defining the prognosis and tailoring therapeutic approaches to LN. Notably, high activity and chronicity indexes were independent predictors of ESRD and CKD at multivariate analysis. Due to the decreasing trend of LN presentation with severe renal dysfunction, these histopathological variables remain a valuable tool aiding the physician in defining prognosis and taking treatment decisions in all patients. ${ }^{41}$ 
Table 3 Univariate Cox proportional hazard regression analysis among the clinical characteristics at presentation of lupus nephritis for end-stage renal disease and chronic kidney disease

\begin{tabular}{|c|c|c|c|c|c|c|}
\hline & \multicolumn{3}{|c|}{ Univariate analysis ESRD } & \multicolumn{3}{|c|}{ Univariate analysis CKD } \\
\hline & RR & $95 \% \mathrm{Cl}$ & $P$ values & RR & $95 \% \mathrm{Cl}$ & $P$ values \\
\hline Year of LN diagnosis & 0.941 & 0.914 to 0.967 & $<0.0001$ & 0.964 & 0.945 to 1.058 & 0.00017 \\
\hline Male gender & 1.84 & 0.810 to 4.188 & 0.14 & 1.53 & 0.824 to 2.836 & 0.18 \\
\hline Age at diagnosis of $\mathrm{LN}$ & 0.998 & 0.969 to 1.027 & 0.9 & 1.01 & 0.987 to 1.026 & 0.5 \\
\hline Duration of SLE before diagnosis of LN & 0.925 & 0.835 to 1.024 & 0.13 & 0.961 & 0.906 to 1.019 & 0.19 \\
\hline $\begin{array}{l}\text { Histological classes: } \\
\text { II+Vvs III+IV }\end{array}$ & 3.01 & 1.067 to 8.456 & 0.037 & 1.79 & 0.987 to 3.251 & 0.055 \\
\hline Activity index* & 1.15 & 1.085 to 1.26 & $<0.0001$ & 1.11 & 1.065 to 1.167 & $<0.0001$ \\
\hline Chronicity index* & 1.39 & 0.935 to 1.531 & $<0.0001$ & 1.3 & 1.197 to 1.414 & $<0.0001$ \\
\hline $\begin{array}{l}\text { Urinary abnormalities+nephrotic syndrome vs } \\
\text { nephritic syndrome+rapidly progressive renal insufficiency }\end{array}$ & 3.19 & 2.202 to 4.620 & $<0.0001$ & 2.35 & 1.88 to 2.943 & $<0.0001$ \\
\hline Log serum creatininet & 5.03 & 3.52 to 7.26 & $<0.0001$ & 3.72 & 2.838 to 4.838 & $<0.0001$ \\
\hline Creatinine clearance & 0.967 & 0.864 to 1.082 & $<0.0001$ & 0.974 & 0.967 to 0.981 & $<0.0001$ \\
\hline Proteinuria $g / 24$ hours & 1.04 & 0.969 to 1.110 & 0.28 & 1.03 & 0.979 to 1.083 & 0.24 \\
\hline Urinary erythrocytes & 0.996 & 0.984 to 1.008 & 0.56 & 1.002 & 0.997 to 1.006 & 0.46 \\
\hline Serum albumin & 0.551 & 0.36 to 0.84 & 0.0058 & 0.716 & 0.53 to 0.96 & 0.026 \\
\hline Arterial hypertension & 8.35 & 3.277 to 21.177 & $<0.0001$ & 4.15 & 2.480 to 6.900 & $<0.0001$ \\
\hline Haematocrit & 0.91 & 0.875 to 0.946 & $<0.0001$ & 0.926 & 0.899 to 0.953 & $<0.0001$ \\
\hline White blood cell count & 1 & 1.000 to 1.000 & $<0.0001$ & 1 & 1.000 to 1.000 & 0.008 \\
\hline Platelet count & 1 & 1.000 to 1.000 & 0.33 & 1 & 1.000 to 1.000 & 0.07 \\
\hline C3 & 0.993 & 0.979 to 1.005 & 0.26 & 0.997 & 0.988 to 1.005 & 0.5 \\
\hline C4 & 0.998 & 0.977 to 0.995 & 0.8 & 0.997 & 0.982 to 1.011 & 0.68 \\
\hline Methyprednisolone pulses/oral prednisolone & 1.01 & 0.45 to 2.26 & 0.97 & 0.913 & 0.530 to 1.571 & 0.74 \\
\hline Immunosuppressive induction therapy & 2.23 & 1.079 to 4.623 & 0.03 & 0.724 & 0.420 to 1.244 & 0.24 \\
\hline Immunosuppressive maintenance therapy & 0.693 & 0.34 to 1.41 & 0.31 & 0.857 & 0.53 & 1.38 \\
\hline
\end{tabular}

*For any unit increase in activity or in chronicity index.

tFor any unit increase in log serum creatinine.

Significant $P$ values are given in bold.

C3/C4, complement components; CKD, chronic kidney disease; ESRD, end-stage renal disease; LN, lupus nephritis; SLE, systemic lupus erythematosus.

Arterial hypertension was another important predictor of both ESRD and CKD. ${ }^{34} 42-44$ Thus, the effective control of blood pressure is of paramount importance in the management of LN. In keeping with previous reports, ${ }^{45-48}$ male gender was associated with worse renal outcome in our cohort; however, according to a recent critical review of the literature, there is limited evidence supporting the worse prognosis in male than in female patients. ${ }^{49}$

Table 4 Predictors of chronic kidney disease, end-stage renal disease and death at multivariate Cox proportional hazards regression analysis

\begin{tabular}{|c|c|c|c|c|}
\hline & Coefficient & RR & $95 \% \mathrm{Cl}$ & $P$ value \\
\hline \multicolumn{5}{|l|}{ Dependent variable: chronic kidney disease } \\
\hline Logarithm of serum creatinine & 0.8708 & $2.39^{*}$ & 1.57 to 3.65 & $<0.0001$ \\
\hline Chronicity index & 0.1188 & $1.13 \dagger$ & 1.01 to 1.26 & 0.034 \\
\hline Hypertension & 1.4243 & 4.16 & 2.15 to 8.03 & $<0.0001$ \\
\hline No immunosuppressive drugs for maintenance & 0.7341 & 2.08 & 1.14 to 3.82 & 0.018 \\
\hline Male gender & 1.2057 & 3.34 & 1.25 to 8.93 & 0.016 \\
\hline Activity index & 0.0936 & $1.1+$ & 1.02 to 1.19 & 0.02 \\
\hline Chronicity index & 0.2545 & $1.29+$ & 1.11 to 1.49 & 0.00069 \\
\hline Hypertension & 1.7835 & 5.95 & 1.99 to 17.75 & 0.0014 \\
\hline No immunosuppressive drugs for maintenance & 1.1106 & 3.04 & 1.37 to 6.74 & 0.0063 \\
\hline
\end{tabular}

Clinical characteristics at presentation of lupus nephritis were analysed as independent variables.

${ }^{*}$ For any unit increase in log serum creatinine.

tFor any unit increase in activity or in chronicity index.

¥For any increase in 1 year of age.

$\mathrm{RR}$, relative risk. 
We observed that the proportion of male patients progressively increased over time, but we have no explanation for the increase in number of men diagnosed in the last decades and we think that this preliminary result needs to be confirmed in large multicentre studies. Another interesting result of our study is the significant and progressive improvement of renal survival from $\mathrm{P} 1$ to $\mathrm{P} 3$, which confirms previous data ${ }^{10-13}$ and is probably the result of a wider indication to renal biopsy and improved treatment of LN over the last decades. ${ }^{48}$

We are aware of a number of limitations of this study. It is a retrospective study of prospectively collected data and no information is provided on the number of patients who achieved remission after induction therapy, the duration of remission, the number of flares and the need of repeated renal biopsy. The majority of our patients were Caucasian; hence, the results may not be applied to other ethnic groups.

In conclusion, the clinical presentation at the time of kidney biopsy for suspected LN has apparently become less severe in the last years and is now characterised by an increase in isolated urinary abnormalities and a decrease in renal insufficiency. However, a concomitant decrease in histological active lesions was not observed. This emphasises once again the importance of performing renal biopsy in the management of LN. The progressive improvement in renal survival in our cohort is the result of a comprehensive approach, which includes a prompt diagnosis of renal involvement, a wider indication to renal biopsy, treatment based on renal biopsy and increased clinical experience in the management of LN.

Acknowledgements We would like to thank Marina Balderacchi and Andrea Centa for their secretarial assistance. We would like to thank Dr Pietro Napodano for providing us patients' information.

Contributors GM, AD and RAS contributed to the conception and design of the work, interpreted the data, drafted and revised the manuscript for important intellectual content. SQ and LS contributed to the statistical analysis. PGV, MG, DG, GC, FR, MZ and MLU followed up patients and contributed to the acquisition of data. PM, FP and AV critically revised the final work. All the authors approved the final version of the manuscript and gave their agreement to be accountable for all aspects of the work in ensuring that questions related to the accuracy or integrity of any part of the work are appropriately investigated and resolved.

Funding The authors have not declared a specific grant for this research from any funding agency in the public, commercial or not-for-profit sectors.

Competing interests None declared.

Patient consent Not required.

Ethics approval Ethics Committee of the Azienda Ospedaliera-Università degli Studi di Padova, Padua, Italy; Ospedale Maggiore Policlinico, Milan, Italy.

Provenance and peer review Not commissioned; externally peer reviewed.

Data sharing statement There are no additional unpublished data from this study to share.

(c) Article author(s) (or their employer(s) unless otherwise stated in the text of the article) 2018. All rights reserved. No commercial use is permitted unless otherwise expressly granted.

\section{REFERENCES}

1 Ponticelli C, Moroni G. Flares in lupus nephritis: incidence, impact on renal survival and management. Lupus 1998;7:635-8.

2 Doria A, laccarino L, Ghirardello A, et al. Long-term prognosis and causes of death in systemic lupus erythematosus. Am J Med 2006;119:700-6.

3 Yap DYH, Tang C, Ma MKM, et al. Longterm data on disease flares in patients with proliferative lupus nephritis in recent years. J Rheumatol 2017;44:1375-83.

4 Zen M, Bassi N, Nalotto L, et al. Disease activity patterns in a monocentric cohort of SLE patients: a seven-year follow-up study. Clin Exp Rheumatol 2012;30:856-63.

5 Cameron JS. Lupus nephritis. J Am Soc Nephrol 1999;10:413-24.

6 Hanly JG, Su L, Urowitz MB, et al. A longitudinal analysis of outcomes of lupus nephritis in an international inception cohort using a multistate model approach. Arthritis Rheumatol 2016;68:1932-44.
7 Moroni G, Depetri F, Ponticelli C. Lupus nephritis: when and how often to biopsy and what does it mean? J Autoimmun 2016;74:27-40.

8 Cervera R, Abarca-Costalago M, Abramovicz D, et al. Systemic lupus erythematosus in Europe at the change of the millennium: lessons from the "Euro-Lupus Project". Autoimmun Rev 2006;5:180-6.

9 Yap DY, Tang CS, Ma MK, et al. Survival analysis and causes of mortality in patients with lupus nephritis. Nephrol Dial Transplant 2012;27:3248-54.

10 Moroni G, Quaglini S, Gallelli B, et al. Progressive improvement of patient and renal survival and reduction of morbidity over time in patients with lupus nephritis (LN) followed for 20 years. Lupus 2013;22:810-8.

11 Urowitz MB, Gladman DD, Tom BD, et al. Changing patterns in mortality and disease outcomes for patients with systemic lupus erythematosus. J Rheumatol 2008;35:2152-8.

12 Fiehn C, Hajjar Y, Mueller K, et al. Improved clinical outcome of lupus nephritis during the past decade: importance of early diagnosis and treatment. Ann Rheum Dis 2003;62:435-9.

13 Tektonidou MG, Dasgupta A, Ward MM. Risk of end-stage renal disease in patients with lupus nephritis, 1971-2015: a systematic review and Bayesian meta-analysis. Arthritis Rheumatol 2016;68:1432-41.

14 Gatto M, laccarino L, Ghirardello A, et al. Clinical and pathologic considerations of the qualitative and quantitative aspects of lupus nephritogenic autoantibodies: a comprehensive review. J Autoimmun 2016;69:1-11.

15 Hochberg MC. Updating the American College of Rheumatology revised criteria for the classification of systemic lupus erythematosus. Arthritis Rheum 1997:40:40.

16 Weening JJ, D'Agati VD, Schwartz MM, et al. The classification of glomerulonephritis in systemic lupus erythematosus revisited. Kidney Int 2004;65:521-30.

17 Austin HA, Boumpas DT, Vaughan EM, et al. Predicting renal outcomes in severe lupus nephritis: contributions of clinical and histologic data. Kidney Int 1994;45:544-50.

18 Venables WN, Ripley BD. Modern applied statistics with S-PLUS. 3rd edn. New York, Heidelberg: Springer, 1999.

19 Felson DT, Anderson J. Evidence for the superiority of immunosuppressive drugs and prednisone over prednisone alone in lupus nephritis. Results of a pooled analysis. $N$ Engl J Med 1984;311:1528-33.

20 Cathcart ES, Idelson BA, Scheinberg MA, et al. Beneficial effects of methylprednisolone "pulse" therapy in diffuse proliferative lupus nephritis. Lancet 1976;1:163-6

21 Ponticelli C, Tarantino A, Pioltelli P, et al. High-dose methylprednisolone pulses in active lupus nephritis. Lancet 1977;1:1063.

22 Austin HA, Klippel JH, Balow JE, et al. Therapy of lupus nephritis. Controlled trial of prednisone and cytotoxic drugs. N Eng/ J Med 1986;314:614-9.

23 Mok CC, Ying KY, Tang S, et al. Predictors and outcome of renal flares after successful cyclophosphamide treatment for diffuse proliferative lupus glomerulonephritis. Arthritis Rheum 2004;50:2559-68.

24 Henderson L, Masson P, Craig JC, et al. Treatment for lupus nephritis. Cochrane Database Syst Rev 2012;12:CD002922.

25 Hahn BH, McMahon MA, Wilkinson A, et al. American College of Rheumatology guidelines for screening, treatment, and management of lupus nephritis. Arthritis Care Res 2012:64:797-808.

26 Bertsias GK, Tektonidou M, Amoura Z, et al. Joint European League against Rheumatism and European Renal Association-European Dialysis and Transplant Association (EULAR/ERA-EDTA) recommendations for the management of adult and paediatric lupus nephritis. Ann Rheum Dis 2012;71:1771-82.

27 Ponticelli C, Moroni G. Hydroxychloroquine in systemic lupus erythematosus (SLE) Expert Opin Drug Saf 2017:16:411-9.

28 Galindo-Izquierdo M, Rodriguez-Almaraz E, Pego-Reigosa JM, et al. Characterization of patients with lupus nephritis included in a large cohort from the Spanish Society of Rheumatology Registry of Patients With Systemic Lupus Erythematosus (RELESSER). Medicine 2016;95:e2891.

29 Mok CC. Mycophenolate mofetil for non-renal manifestations of systemic lupus erythematosus: a systematic review. Scand J Rheumatol 2007;36:329-37.

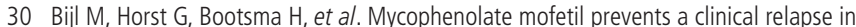
patients with systemic lupus erythematosus at risk. Ann Rheum Dis 2003;62:534-9.

31 Furie $\mathrm{R}$, Petri M, Zamani $\mathrm{O}$, et al. A phase III, randomized, placebo-controlled study of belimumab, a monoclonal antibody that inhibits B lymphocyte stimulator, in patients with systemic lupus erythematosus. Arthritis Rheum 2011;63:3918-30.

32 laccarino L, Bettio S, Reggia R, et al. Effects of belimumab on flare rate and expected damage progression in patients with active systemic lupus erythematosus. Arthritis Care Res 2017:69:115-23.

33 Moroni G, Quaglini S, Gallelli B, et al. The long-term outcome of 93 patients with proliferative lupus nephritis. Nephrol Dial Transplant 2007:22:2531-9.

34 Contreras G, Pardo V, Cely C, et al. Factors associated with poor outcomes in patients with lupus nephritis. Lupus 2005;14:890-5.

35 Sloan RP, Schwartz MM, Korbet SM, et al. Long-term outcome in systemic lupus erythematosus membranous glomerulonephritis. Lupus Nephritis Collaborative Study Group. J Am Soc Nephrol 1996;7:299-305.

36 Adler SG, Johnson K, Louie JS, et al. Lupus membranous glomerulonephritis: different prognostic subgroups obscured by imprecise histologic classifications. Mod Pathol 1990;3:186-91. 
37 Moroni G, Quaglini S, Gravellone L, et al. Membranous nephropathy in systemic lupus erythematosus: long-term outcome and prognostic factors of 103 patients. Semin Arthritis Rheum 2012;41:642-51.

38 Wong SN, Chan WK, Hui J, et al. Membranous lupus nephritis in Chinese children-a case series and review of the literature. Pediatr Nephrol 2009:24:1989-96.

39 Zabaleta-Lanz ME, Muñoz LE, Tapanes FJ, et al. Further description of early clinically silent lupus nephritis. Lupus 2006;15:845-51.

40 Wakasugi D, Gono T, Kawaguchi Y, et al. Frequency of class III and IV nephritis in systemic lupus erythematosus without clinical renal involvement: an analysis of predictive measures. J Rheumatol 2012;39:79-85.

41 Rijnink EC, Teng YKO, Wilhelmus S, et al. Clinical and histopathologic characteristics associated with renal outcomes in lupus nephritis. Clin J Am Soc Nephrol 2017;12:734-43.

42 Ginzler EM, Felson DT, Anthony JM, et al. Hypertension increases the risk of renal deterioration in systemic lupus erythematosus. J Rheumatol 1993;20:1694-700.
43 Korbet SM, Lewis EJ, Schwartz MM, et al. Factors predictive of outcome in severe lupus nephritis. Lupus Nephritis Collaborative Study Group. Am J Kidney Dis 2000;35:904-14.

44 Momtaz M, Fayed A, Wadie M, et al. Retrospective analysis of nephritis response and renal outcome in a cohort of 928 Egyptian lupus nephritis patients: a university hospital experience. Lupus 2017;26:1564-70.

45 Resende AL, Titan SM, Barros RT, et al. Worse renal outcome of lupus nephritis in male patients: a case-control study. Lupus 2011:20:561-7.

46 Schwartzman-Morris J, Putterman C. Gender differences in the pathogenesis and outcome of lupus and of lupus nephritis. Clin Dev Immunol 2012;2012:1-9.

47 Ding Y, He J, Guo JP, et al. Gender differences are associated with the clinical features of systemic lupus erythematosus. Chin Med J 2012;125:2477-81.

48 Ponticelli C, Glassock RJ, Moroni G. Induction and maintenance therapy in proliferative lupus nephritis. J Nephrol 2010;23:9-16.

49 Murphy $\mathrm{G}$, Isenberg D. Effect of gender on clinical presentation in systemic lupus erythematosus. Rheumatology 2013;52:2108-15. 